\title{
A Cross-sectional Study of Patient Satisfaction With the Quality of Care in Ghana From an Adolescent's Perspective
}

\author{
Emmanuel Anongeba Anaba ${ }^{1 *}$, Moses Abile ${ }^{2}$, Grace Adjei Okai ${ }^{3}$ \\ ${ }^{1}$ Department of Population, Family and Reproductive Health, School of Public Health, University of Ghana, Accra, \\ Ghana \\ ${ }^{2}$ Department of Nursing, Nursing and Midwifery Training College, Gushegu, Ghana \\ ${ }^{3}$ Department of Public Administration and Health Service Management, Business School, University of Ghana, Accra, \\ Ghana
}

*Corresponding Author: Emmanuel Anongeba Anaba, Department of Population, Family and Reproductive Health, School of Public Health, University of Ghana, Accra, Ghana. Tel: +233-241787287, Email: emmaanaba24@gmail.com

Received April 21, 2020; Accepted August 30, 2020; Online Published September 8, 2020

\begin{abstract}
Background: Assessing patient satisfaction with care is crucial for healthcare quality improvement. However, little is known about patient satisfaction with care in adolescent-friendly health facilities in Ghana.

Objectives: This study aimed to assess patient satisfaction with quality of healthcare in adolescent-friendly health facilities.

Methods: A cross-sectional survey was conducted of four adolescent-friendly health facilities in Tema, Ghana. In all, 386 adolescent clients/patients were recruited using the convenience sampling technique. A structured questionnaire was administered to respondents, and data was analyzed using Statistical Package for Social Sciences (SPSS) software, version 22.0.

Results: It was found that the majority $(62 \%)$ of respondents were satisfied with the quality of care in adolescent-friendly health facilities. It was also found that overall satisfaction with quality of care was significantly influenced by the availability of health information materials $(\mathrm{AOR}=4.99 ; 95 \% \mathrm{Cl}$ : 1.90-3.96) and positive provider attitudes ( $\mathrm{AOR}=25.76 ; 95 \% \mathrm{Cl}$ : 8.01-109.78).

Conclusion: This study demonstrated that most adolescents were satisfied with the quality of care in adolescent-friendly health facilities. This is one of the few studies that have assessed adolescent satisfaction with the quality of care in Ghana. Stakeholders can leverage these findings to improve the quality of adolescent health services.

Keywords: Adolescent, Patient Satisfaction, Cross-sectional Studies, Adolescent Health Services, Ghana, Quality Improvement
\end{abstract}

\section{Background}

Adolescence is the period between age 10 and 19 years. It is a transitional period from childhood to adulthood characterized by rapid physical, psychosocial, and cognitive development, including puberty. ${ }^{1}$ Adolescents are perceived to be healthy; however, they engage in health risk behaviors which may lead to unintended pregnancies and sexually transmitted infections like HIV. For instance, approximately 16 million girls aged 15-19 years and 2.5 million girls under 16 years of age give birth each year in developing countries. ${ }^{2}$ About 3 million girls aged 15-19 years practice unsafe abortion every year. ${ }^{3}$ Moreover, about 2 million adolescents are living with HIV globally, ${ }^{4}$ with over $41 \%$ of new HIV infections occurring among adolescents. ${ }^{5}$

In the quest to promote adolescent health and wellbeing, the World Health Organization (WHO) is urging member countries to implement standard-driven approaches to improve the quality of adolescent health services. ${ }^{1}$ Thus, health services for adolescents should be accessible, acceptable, appropriate, and affordable. This is partly due to the fact that healthcare services for adolescents are highly fragmented, poorly coordinated, and uneven in quality. ${ }^{1}$ Some developed and developing countries, such as the United States of America and South Africa, have implemented these standards through the establishment of adolescent-friendly health facilities. ${ }^{1}$

In Ghana, adolescent health, wellbeing, and development have been recognized as important. ${ }^{6,7}$ Ghana has high rates of adolescent births, unwanted pregnancies, unsafe abortions, and incidence of sexually transmitted diseases including HIV. ${ }^{7}$ In this regard, some measures have been implemented to make healthcare services and ageappropriate information available and accessible to all adolescents. For instance, Ghana launched the Adolescent Health and Development program in 1996 to provide adolescents with age-appropriate and accurate health information so they could make informed choices ${ }^{7,8}$ and

Copyright (C) 2020 The Author(s). This is an open-access article distributed under the terms of the Creative Commons Attribution License (http:// creativecommons.org/licenses/by/4.0), which permits unrestricted use, distribution, and reproduction in any medium, provided the original work is properly cited. 
developed adolescent health policies and strategies. ${ }^{7}$ In addition, adolescent-friendly health services have been integrated into primary healthcare through the setting up of adolescent health facilities popularly known in Ghana as Adolescent Corners (ACs). ${ }^{7}$ In 2015, the Adolescent Health and Development program received financial and technical support from development partners such as UKAID. In the same year, new ACs were established, health providers were trained, and logistics were procured coupled with the distribution of health information materials including booklets and leaflets. ${ }^{7}$

Despite these efforts, evidence suggests that adolescents' utilization of health services has not improved significantly over time. ${ }^{9}$ Also, access to age-appropriate health information remains low, ${ }^{9,10}$ suggesting that there has been overemphasis on the quantity of health services with little emphasis on quality. It is probable that adolescents are dissatisfied with the quality of services provided in adolescent-friendly health facilities; however, there is a paucity of literature to substantiate this claim.

Studies have shown that patient/client satisfaction is crucial and a major determinant of quality of care. ${ }^{11,12}$ Evidence shows that clients who are satisfied with healthcare are more likely to comply with the prescribed medical regimen, provide relevant information for accurate diagnosis, and continue using health services. ${ }^{13,14}$ Furthermore, patient satisfaction influences healthcare utilization behaviors, such as where to access services, how much clients are willing to pay, continuity of utilization, and whether clients will recommend services to others. ${ }^{12,15}$ Satisfied clients are likely to purchase more services, remain loyal, and give positive word-of-mouth recommendations, while dissatisfied clients are two times more likely to spread negative experiences and less likely to patronize healthcare facilities in the future. ${ }^{11,16}$

Nonetheless, there is a paucity of literature on adolescent satisfaction with quality of care in Ghana. To the best of the authors' knowledge, this is the maiden study in Ghana that assesses patient satisfaction with quality of care from an adolescent's perspective. Understanding the salient factors that influence adolescent satisfaction with quality of care is crucial for adolescent healthcare quality improvement. ${ }^{13,14}$ In addition, adolescents' views are hardly considered in patient satisfaction surveys. This study, therefore, provides baseline information for future studies.

\section{Objectives}

The Ministry of Health in Ghana has acknowledged adolescent health problems as public health issues. The Adolescent Health and Development program was, therefore, implemented to promote access to healthcare among adolescents. However, the effectiveness of the program has not been evaluated. The evaluation of the program is therefore crucial and needful for quality improvement and accountability purposes. The objective of this study was to assess adolescents' satisfaction with the quality of care in adolescent health facilities. The study sought to identify the salient factors associated with adolescent satisfaction with quality of care. Findings of this study have the potential to inform future adolescent health policies and programs.

\section{Methods}

A cross-sectional survey was conducted of 4 adolescentfriendly health facilities in Tema Metropolis, Ghana. The survey was conducted between January and March 2017. The metropolis is an urban setting located in the eastern part of Accra, Ghana's capital town. As of 2010, the metropolis had a population of 292773 , of which $18.9 \%$ (55334) were adolescents. The metropolis has a high literacy rate of $91.1 \% .{ }^{17}$ The study setting has Ghana's largest harbor and is well known for industrial activities. The metropolis has high incidence rates of HIV infections and pregnancies among adolescents. There are 4 public health facilities including a hospital, a polyclinic, a health center, and a clinic. There are many private health facilities that complement the public ones. There are 4 ACs in the metropolis, which are attached to the public health facilities. The ACs are operated by trained nurses with a focal person at the Metropolitan Directorate, who is responsible for coordinating the activities of all the ACs. The ACs provides wide range of health services including counseling, family planning, health education, and HIV testing among others.

The target population for this study was adolescents who visited the ACs. The ACs record an average annual attendance of about 2000 adolescents. In all, 386 adolescent clients/patients were recruited from the $4 \mathrm{ACs}$, using the convenience sampling technique. This approach was adopted due to the low turnout in the ACs. Prior to the selection of participants, the 4 ACs were purposely selected. Adolescents who did not visit the ACs during the study period were excluded. Moreover, this study was facility-based and included adolescents in the community.

Data collection was done at the ACs through exit interviews and on the spot collection of completed questionnaires. Adolescent clients who were interested in participating in this study were asked to sign an assent form, while their parents/guardians signed a consent form. In addition, permission was sought from the management of the ACs prior to data collection. This study had the approval of the Ghana Health Service Ethical Review Board. Participation was voluntary and participants had the free will to exit the study prior to completion of the interview. Data was collected by the first author between January and March 2017 using a structured questionnaire categorized into two main sections. The first section comprised socio-demographic variables (5 items), i.e. gender, age, educational status, occupation, and marital status. The second section of the questionnaire comprised 5 quality-of-care dimensions adopted from the WHO and had been used in similar contexts. ${ }^{1,18}$ The dimensions included availability of health information, health facility characteristics, appropriateness of care, 
provider attitude, and non-discrimination. All dimensions had 5 dummy variables each coded as $1=$ 'yes', $0=$ 'no'. In addition, overall satisfaction was assessed using a single item on a 5 -point ordinal scale ranging from $1=$ very dissatisfied to 2 = dissatisfied, 3 = neutral, $4=$ satisfied, and $5=$ very satisfied. The questionnaire was designed and administered in English. In order to ensure validity, the questionnaire was designed in consultation with adolescent health professionals and senior researchers. The questionnaire was pilot tested with 12 adolescents in a different region, and the findings were incorporated in the final questionnaire. Cronbach's Alpha test was used to compute reliability. The reliability coefficient was 0.83 , which is higher than the recommended 0.7. ${ }^{19}$ Hence, the questionnaire was valid and reliable. For respondents who did not understand English, items on the questionnaire were translated orally into the local dialect (Twi language) by the interviewer.

Data was analyzed using Statistical Package for Social Science (SPSS) software, version 22 and in 3 stages: univariate, bivariate, and multivariate analyses. In the first stage, frequency, percentage, mean and standard deviation were computed. In the second stage, chi-square analysis was computed to assess the association between the dimensions of quality of care and satisfaction. Prior to computing the chi-square, the dependent variables were categorized into $0=$ 'dissatisfied' and $1=$ 'satisfied'. In the third stage of the analysis, logistic regression was computed to determine the significant predictors of adolescent satisfaction with quality of care. In this stage, the items under each dimension (predictors) were computed to generate a composite score, which was then categorized into 'Poor' and 'Good'. All results were reported at the 0.05 significance level.

\section{Results}

4.1. Socio-demographic Characteristics of Respondents It was found that the majority of the respondents were females $(69.3 \%)$, above the age of 15 years $(68.3 \%)$ with a mean age of $16.4 \pm 1.8$. The majority (69\%) of respondents had attained a junior high school education, and about 6 in 10 respondents were currently in school. Details are provided in Table 1. Exactly, $62 \%$ of the respondents were satisfied with the quality of care.

\subsection{Bivariate Analysis}

A statistically significant association was found between availability of sign posts directing clients to the AC and satisfaction $\left(\chi^{2}=44.97, P<0.001\right)$. Similarly, a significant association was found between availability of health information materials such as booklets and satisfaction $\left(\chi^{2}=37.62, P<0.001\right)$. In addition, adolescent satisfaction was significantly associated with awareness of available services $\left(\chi^{2}=20.16, P<0.001\right)$. Availability of supplies, such as medication, was also associated with satisfaction $\left(\chi^{2}=18.25, P<0.001\right)$. Appropriateness of the services provided, such as availability of pregnancy testing $\left(\chi^{2}=\right.$
Table 1. Demographic Characteristics of Respondents Participating in Adolescent Satisfaction Survey $(\mathrm{n}=386)$

\begin{tabular}{|c|c|c|}
\hline Characteristic & $\mathbf{n}$ & $\%$ \\
\hline \multicolumn{3}{|l|}{ Gender } \\
\hline Male & 188 & 30.7 \\
\hline Female & 266 & 69.3 \\
\hline \multicolumn{3}{|l|}{ Age $(y)$} \\
\hline $10-13$, Mean $=16.4 \pm 1.8$ & 23 & 6.1 \\
\hline $14-15$ & 97 & 25.6 \\
\hline $16-17$ & 140 & 36.9 \\
\hline $18-19$ & 119 & 31.4 \\
\hline \multicolumn{3}{|l|}{ Educational status } \\
\hline None & 17 & 4.4 \\
\hline Primary & 49 & 12.8 \\
\hline Junior high & 265 & 69.0 \\
\hline$\geq$ Senior high & 53 & 13.8 \\
\hline \multicolumn{3}{|l|}{ Marital status } \\
\hline Unmarried & 337 & 87.8 \\
\hline Married & 26 & 6.8 \\
\hline Cohabitating & 21 & 5.5 \\
\hline \multicolumn{3}{|l|}{ Occupation } \\
\hline Schooling & 229 & 59.8 \\
\hline Trading & 53 & 13.8 \\
\hline Apprenticeship & 68 & 9.9 \\
\hline Unemployment & 83 & 16.4 \\
\hline
\end{tabular}

7.39, $P=0.007)$, counseling services $\left(\chi^{2}=7.18, P=0.008\right)$, and availability of sexually transmitted infection testing $\left(\chi^{2}=4.71, \quad P=0.033\right)$, was significantly associated with satisfaction. Furthermore, respondents who had adequate consultation time $\left(\chi^{2}=19.20, P<0.001\right)$, enough confidentiality $\left(\chi^{2}=23.91, P<0.001\right)$, clearly understood the consultation $\left(\chi^{2}=24.22, P<0.001\right)$, and were treated respectfully $\left(\chi^{2}=17.65, P<0.001\right)$ were more likely to be satisfied. The results also showed that respondents who did not experience discrimination were more likely to be satisfied $\left(\chi^{2}=5.27, P=0.025\right)$. Details are provided in Table 2.

\subsection{Multivariate Analysis}

In the crude analysis, it was found that perception about availability of health information, provider attitude, and appropriateness of care were significant predictors of adolescent satisfaction with quality of care. For instance, adolescents who perceived the availability of health information to be good had higher odds (crude odds ratio $[\mathrm{COR}]=0.15 .73 ; 95 \% \mathrm{CI}: 0.19-0.57)$ of being satisfied with the quality of care. Adolescents who perceived provider attitude to be good also had higher odds ( $\mathrm{COR}=33.79$; 95\% CI: 0.01-0.08) of being satisfied with the quality of care. In addition, adolescents who perceived the care to be more appropriate had higher odds (COR $=9.18$; $95 \%$ CI: $0.17-0.69$ ) of being satisfied with the quality of care. In the adjusted analysis, it was found that adolescents who perceived the availability of health information to be good were 5 times more likely (adjusted odds ratio $[\mathrm{AOR}]=$ 
Table 2. Descriptive Statistics of Adolescent Satisfaction With Quality of Care in Adolescent-Friendly Health Facilities in Tema Metropolis $(\mathrm{n}=386$ )

\begin{tabular}{|c|c|c|c|c|c|c|}
\hline Dimensions & & $\mathbf{n}$ & Dissatisfied \% & Satisfied \% & Chi-square & $P$ Value \\
\hline \multicolumn{7}{|l|}{ Availability of health information } \\
\hline \multirow{2}{*}{ Did you see any sign post directing you to the $A C$ ? } & Yes & 171 & 19 & 81 & \multirow{2}{*}{44.97} & \multirow{2}{*}{$<0.001$} \\
\hline & No & 206 & 53 & 47 & & \\
\hline \multirow{2}{*}{ Did you get books/flyers to read at the AC? } & Yes & 225 & 25 & 75 & \multirow{2}{*}{37.62} & \multirow{2}{*}{$<0.001$} \\
\hline & No & 152 & 57 & 43 & & \\
\hline \multirow{2}{*}{ Were you given books/flyers to take home? } & Yes & 115 & 32 & 68 & \multirow{2}{*}{2.25} & \multirow{2}{*}{0.136} \\
\hline & No & 263 & 40 & 60 & & \\
\hline \multirow{2}{*}{ Did any staff member inform you about services at the AC? } & Yes & 248 & 30 & 70 & \multirow{2}{*}{20.16} & \multirow{2}{*}{$<0.001$} \\
\hline & No & 129 & 54 & 46 & & \\
\hline \multirow{2}{*}{ Did any staff member talk to you about how to prevent diseases? } & Yes & 333 & 35 & 65 & \multirow{2}{*}{8.64} & \multirow{2}{*}{0.005} \\
\hline & No & 45 & 58 & 42 & & \\
\hline \multicolumn{7}{|l|}{ Health facility characteristics } \\
\hline \multirow{2}{*}{ Are you comfortable with the location of the AC? } & Yes & 144 & 37 & 63 & 010 & 0.827 \\
\hline & No & 234 & 39 & 61 & 0.10 & 0.023 \\
\hline Are vou comfortable with the onerating hours of the $A C ?$ & Yes & 258 & 40 & 60 & 151 & 0255 \\
\hline : & No & 120 & 33 & 67 & 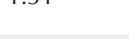 & 0.230 \\
\hline Did you get enough privacy at the AC? & Yes & 273 & 39 & 61 & 078 & 0.404 \\
\hline 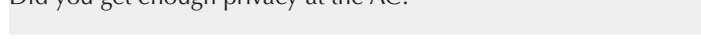 & No & 103 & 34 & 66 & 0.07 & 0.7 T \\
\hline Was the environment of the AC welcoming? & Yes & 345 & 37 & 63 & 025 & 0700 \\
\hline 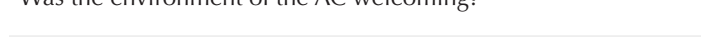 & No & 31 & 42 & 58 & 0.23 & 0.700 \\
\hline Did you get all your supplies from the AC? & Yes & 176 & 49 & 51 & 1825 & $<0,001$ \\
\hline 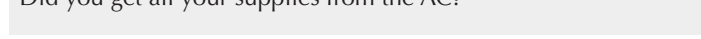 & No & 203 & 28 & 72 & 10.25 & -0.001 \\
\hline Appropriateness of care & & & & & & \\
\hline Availability of nregnancy testino? & Yes & 323 & 35 & 65 & 739 & 0007 \\
\hline Avallatity or pregnancy tesming? & No & 55 & 55 & 45 & 1.59 & 0.007 \\
\hline Availability of counselino services? & Yes & 318 & 35 & 65 & 718 & 0008 \\
\hline 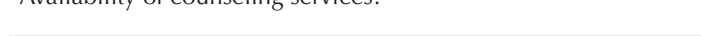 & No & 58 & 53 & 47 & 1.10 & 0.000 \\
\hline Availability of family planning services? & Yes & 292 & 37 & 63 & 0.34 & 0.610 \\
\hline & No & 84 & 41 & 69 & 0.34 & 0.010 \\
\hline Availability of STI testing? & Yes & 324 & 40 & 60 & 471 & 0033 \\
\hline 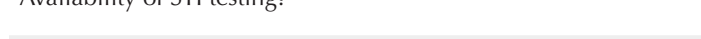 & No & 53 & 24 & 76 & (1) & (0.0 \\
\hline Availability of outreach services? & Yes & 180 & 35 & 65 & 1.40 & 0245 \\
\hline Avallabinty or outreacn services? & No & 198 & 41 & 59 & 1.40 & 0.243 \\
\hline Provider attitudes & & & & & & \\
\hline Did the staff spend enough time to listen to you? & Yes & 348 & 35 & 65 & 1920 & $<0001$ \\
\hline 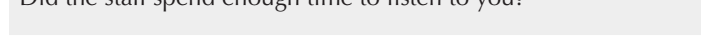 & No & 29 & 76 & 24 & 19.20 & $<0.001$ \\
\hline Did the staff talk to you in a respectful manner? & Yes & 355 & 35 & 65 & 1765 & $<0001$ \\
\hline & No & 21 & 81 & 19 & 17.00 & \\
\hline Did the staff assure you of confidentiality? & Yes & 317 & 33 & 67 & 2201 & $<0001$ \\
\hline 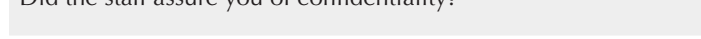 & No & 59 & 66 & 34 & 20.51 & -0.001 \\
\hline Did the staff explain SRH issues to your understanding? & Yes & 335 & 33 & 67 & 24.22 & $<0,001$ \\
\hline & No & 43 & 72 & 28 & 24.22 & 20.001 \\
\hline Did the staff condemn vour decisions? & Yes & 57 & 39 & 61 & 0.05 & 0882 \\
\hline & No & 318 & 37 & 63 & & \\
\hline Non-discrimination & & & & & & \\
\hline Was there a display explaining that services would be provided & Yes & 181 & 25 & 75 & 24.73 & $<0.001$ \\
\hline without discrimination? & No & 195 & 50 & 50 & & \\
\hline Were you denied any service because of your inability to pay? & Yes & 57 & 39 & 61 & 0.02 & 0888 \\
\hline vere you demea any service decause or your mandinty to pay? & No & 319 & 38 & 62 & 0.02 & 0.000 \\
\hline Were you denied any service because of your gender? & Yes & 32 & 28 & 72 & 1.43 & 0.259 \\
\hline & No & 345 & 39 & 61 & & \\
\hline Were you denied any service hecause of your marital status? & Yes & 40 & 35 & 65 & 014 & 0735 \\
\hline 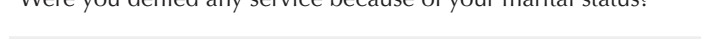 & No & 337 & 38 & 62 & 0.14 & 0.730 \\
\hline Were you denied any service because of your age? & Yes & 48 & 23 & 77 & 5.27 & 0.025 \\
\hline vete you dernea any setvice decause on your age? & No & 329 & 40 & 60 & 3.27 & \\
\hline
\end{tabular}


4.99; $95 \%$ CI: $1.90-3.96)$ to be satisfied with the quality of care in adolescent clinics. Also, adolescents who perceived the attitudes of the providers to be good were about 26 times more likely $(\mathrm{AOR}=25.76 ; 95 \% \mathrm{CI}: 8.01-109.78)$ to be satisfied with the quality of care. Details are provided in Table 3.

\section{Discussion}

Assessing patient satisfaction is crucial for healthcare quality improvement. Yet, little is known about patient satisfaction with healthcare in adolescent-friendly health facilities in Ghana. This study sought to assess adolescents' satisfaction with the quality of healthcare and identify salient factors associated with satisfaction.

The findings showed that the majority of adolescents were satisfied with the quality of care. This finding corroborates findings of existing studies. ${ }^{20-22}$ For example, a similar study in Tanzania found that the majority of adolescents were satisfied with healthcare services. ${ }^{14}$ A recent study in Malaysia also found that patients were more satisfied with healthcare services in adolescent-friendly clinics than those in conventional clinics. ${ }^{23}$ In addition, a comparative study of adolescent-friendly clinics and conventional clinics in India revealed that clients of adolescent-friendly clinics were more likely to be satisfied. ${ }^{24}$ This finding is expected, since healthcare providers in adolescent-friendly health facilities have received training in adolescent healthcare. ${ }^{7}$ Hence, they are expected to demonstrate high levels of professionalism, such as respect, privacy, and confidentiality, which are of much importance to adolescents. ${ }^{25,26}$

In addition, the current study found that adolescent satisfaction with quality of care was significantly influenced by the availability of health information and positive provider attitudes. This implies that adolescents in this study were satisfied with the quality of care, because they received accurate and reliable health information; had access to health information materials; and health providers respected their opinions and privacy. Evidence shows that promoting a friendly relationship between healthcare providers and adolescents is a significant determinant of adolescent satisfaction with care. ${ }^{27,28}$ Kaplan et $\mathrm{al}^{29}$ for instance, found that adolescents who had abusive experiences with healthcare providers were less likely to be satisfied with health services compared to those who did not experience any abuse. ${ }^{30}$ In Tanzania, Masatu et $\mathrm{al}^{14}$ found that adolescents who had discussions with healthcare providers on topics such as sexually transmitted infections were more likely to be satisfied with youthfriendly services.

These findings are expected, since the Adolescent Health and Development program received financial and technical support. Through this support, health information materials in the form of booklets and leaflets were printed and distributed to adolescent-friendly health facilities. In addition, healthcare providers received training in adolescent-friendly care. ${ }^{7}$ These findings have implications for adolescent health promotion. For instance, promoting access to reliable and accurate health information is crucial for all adolescents. Studies have shown that adolescents lack adequate health information and rely mostly on unreliable sources of information such as peers. ${ }^{31,32}$ Consequently, adolescents make uninformed health choices, such as engaging in health risk behaviors, which may have deleterious consequences on their health. On the other hand, adolescents who have access to health information from reliable sources such as health professionals are more likely to make informed choices such as abstaining from pre-marital sexual activities.

In addition, studies have shown that adolescents are more likely to face challenges when accessing health services compared to adults. Some of these challenges include judgmental attitudes, unfriendliness, and discrimination from healthcare providers. ${ }^{8,33,34}$ Such experiences may

Table 3. Binary Logistic Regression of Predictors of Adolescent Satisfaction With Quality of Care in Ghana, 2017

\begin{tabular}{|c|c|c|c|c|}
\hline Covariate/Exposure & $\begin{array}{l}\text { Crude Analysis } \\
\text { OR }(95 \% \mathrm{CI}) \\
\end{array}$ & Wald $P$ Value & $\begin{array}{c}\text { Adjusted Analysis } \\
\text { OR }(95 \% \mathrm{Cl})\end{array}$ & Wald $P$ Value \\
\hline \multicolumn{5}{|c|}{ Availability of health information } \\
\hline $\begin{array}{l}\text { Poor } \\
\text { Good }\end{array}$ & $\begin{array}{c}1 \text { (reference category) } \\
15.73(0.19-0.57)\end{array}$ & $<0.001$ & $\begin{array}{c}1 \text { (reference category) } \\
4.99(1.90-3.96)\end{array}$ & 0.026 \\
\hline \multicolumn{5}{|c|}{ Health facility characteristics } \\
\hline $\begin{array}{l}\text { Poor } \\
\text { Good }\end{array}$ & $\begin{array}{c}1 \text { (reference category) } \\
1.17(0.40-1.30)\end{array}$ & 0.280 & $\begin{array}{c}1 \text { (reference category) } \\
1.80(0.81-3.15)\end{array}$ & 0.246 \\
\hline \multicolumn{5}{|l|}{ Provider attitudes } \\
\hline $\begin{array}{l}\text { Poor } \\
\text { Good }\end{array}$ & $\begin{array}{c}1 \text { (reference category) } \\
33.79(0.01-0.08)\end{array}$ & $<0.001$ & $\begin{array}{c}1 \text { (reference category) } \\
25.76(8.01-109.78)\end{array}$ & $<0.001$ \\
\hline \multicolumn{5}{|c|}{ Appropriateness of care } \\
\hline $\begin{array}{l}\text { Poor } \\
\text { Good }\end{array}$ & $\begin{array}{c}1 \text { (reference category) } \\
9.18(0.17-0.69)\end{array}$ & 0.002 & $\begin{array}{c}1 \text { (reference category) } \\
1.34(0.71-3.86)\end{array}$ & 0.246 \\
\hline \multicolumn{5}{|l|}{ Non-discrimination } \\
\hline $\begin{array}{l}\text { Poor } \\
\text { Good }\end{array}$ & $\begin{array}{c}1 \text { (reference category) } \\
0.29(0.53-3.06)\end{array}$ & 0.590 & $\begin{array}{c}1 \text { (reference category) } \\
2.03(0.19-1.31)\end{array}$ & 0.155 \\
\hline
\end{tabular}


lead to low utilization of professional health services, or adolescents may resort to seeking the services of unprofessional providers such as quack doctors. Therefore, promoting access to accurate health information and quality health services is crucial for adolescent health, wellbeing, and development.

Although the majority of respondents were satisfied with the quality of care, some aspects of the care was below expectations. Notable among them were the low publicity of the health facilities; inadequate health information materials for adolescents to take home; inconvenient location of the health facilities; and shortage of supplies. The majority of respondents perceived the aforementioned aspects of care to be poor. The impact of these setbacks on adolescent satisfaction and utilization of health services cannot be underestimated. Dissatisfied adolescents are less likely to patronize services in the future or recommend such services to their friends. ${ }^{12,15}$ These among other factors may explain why the utilization of health services among Ghanaian adolescents is low. It is, therefore, recommended that stakeholders, including healthcare managers, consider re-equipping adolescent-friendly health facilities with enough health information materials and supplies. Adolescents with health information materials in their possession can study them at their convenience or share them with their friends. It is also recommended that adolescent-friendly health facilities be relocated, because the current locations are not convenient for adolescents. Relocating to a more convenient location would help increase accessibility and utilization of healthcare among adolescents.

Although this study provides relevant information for adolescent healthcare quality improvement, it is not devoid of limitations. It would have been ideal to compare adolescent-friendly health facilities with conventional health facilities. Therefore, it is suggested that future studies explore this gap in knowledge. The findings must be interpreted with caution, because this study was conducted in an urban setting. The findings in rural settings may not be the same. A comparative study of rural and urban adolescent-friendly healthcare facilities is therefore recommended for future studies.

\section{Conclusion}

This study demonstrates that the majority of adolescents were satisfied with the quality of care in adolescent-friendly health facilities. Adolescent satisfaction was influenced by the availability of health information materials and positive provider attitudes. Stakeholders, including the Ministry of Health, can leverage these findings to improve the quality of adolescent health services in Ghana. This study makes a modest contribution to the limited literature on adolescent healthcare.

\section{Authors' Contributions}

All authors contributed significantly toward the successful completion of this publication.
Research Highlights

\section{What Is Already Known?}

Patient satisfaction with quality of care has been explored among adult patients and in general healthcare facilities. Studies among adult patients have shown that patient satisfaction with quality of care is associated with empathy, communication, culture, tangibles, and priority. Additionally, satisfied patients are more likely to purchase more services, remain loyal, and give positive word-ofmouth recommendations, while dissatisfied patients are less likely to patronize services in the future.

\section{What This Study Adds?}

This study is among the few studies, especially in Africa, that have assessed adolescents' satisfaction with quality of care. It is the maiden study in Ghana to assess patient satisfaction in adolescent-friendly health facilities. This study revealed that the majority of adolescents who visit adolescent-friendly clinics are satisfied with the quality of care. Adolescents who had access to age-appropriate health information/materials or perceived healthcare providers to be friendly and respectful were more likely to be satisfied. Stakeholders can leverage these findings to improve adolescent healthcare quality in Ghana and similar settings.

\section{Conflict of Interest Disclosures}

None declared.

\section{Ethical Approval}

This study had the approval of the Ghana Health Service Ethical Review Committee. Permission was sought from the Metropolitan Health Directorate and the management of the various health facilities before commencing data collection.

\section{Acknowledgments}

The authors express their appreciation to the management members of Tema Metropolitan Health Directorate for their warm reception and support during data collection. The authors also thank all adolescents who participated in this study.

\section{References}

1. World Health Organization (WHO), UNAIDS. Global Standards for Quality Health-Care Services for Adolescents: A Guide to Implement A Standards-Driven Approach to Improve the Quality of Health Care Services for Adolescents. WHO; 2015.

2. Neal S, Matthews Z, Frost M, Fogstad H, Camacho AV, Laski L. Childbearing in adolescents aged 12-15 years in low resource countries: a neglected issue. New estimates from demographic and household surveys in 42 countries. Acta Obstet Gynecol Scand. 2012;91(9):1114-1118. doi:10.1111/ j.1600-0412.2012.01467.x.

3. World Health Organization (WHO). Adolescent Pregnancy: Adolescence is a Time of Opportunity During Which a Range of Actions Can be Taken to Set the Stage for Healthy Adulthood: 
Factsheet. WHO; 2014.

4. UNICEF. For Every Child, End AIDS: Seventh Stocktaking Report. New York: UNICEF; 2018.

5. World Health Organization (WHO). A Standards-Driven Approach to Improve the Quality of Health-Care Services for Adolescents: Policy Brief. WHO; 2015.

6. Anaba EA, Abuosi AA. Assessing health care quality in adolescent clinics, implications for quality improvement. Int J Health Gov. 2018;23(4):269-280. doi:10.1108/ijhg-03-20180012 .

7. Ghana Health Service. Policy Strategy and Health Service Adolescent (2016-2020). Ghana: Ghana Health Service; 2015.

8. Abuosi AA, Anaba EA. Barriers on access to and use of adolescent health services in Ghana. J Health Res. 2019;33(3):197-207. doi:10.1108/jhr-10-2018-0119.

9. Ghana Health Service. 2015 Family Health Annual Report. Ghana: Ghana Health Service; 2015.

10. Ghana Health Service. 2014 Family Health Division Report. Ghana: Ghana Health Service; 2014.

11. Ahenkan A, Aduo-Adjei K. Predictors of patient satisfaction with quality of healthcare in university hospitals in Ghana. Hosp Pract Res. 2017;2(1):9-14. doi:10.15171/hpr.2017.03.

12. Atinga RA, Abekah-Nkrumah G, Domfeh KA. Managing healthcare quality in Ghana: a necessity of patient satisfaction. Int J Health Care Qual Assur. 2011;24(7):548-563. doi:10.1108/09526861111160580.

13. SovdT, Mmari K, LipovsekV, Manaseki-Holland S. Acceptability as a key determinant of client satisfaction: lessons from an evaluation of adolescent friendly health services in Mongolia. J Adolesc Health. 2006;38(5):519-526. doi:10.1016/j. jadohealth.2005.03.005.

14. Masatu MC, Klepp KI, Kvåle G. Use of health services and reported satisfaction among primary school adolescents in Arusha, Tanzania. J Adolesc Health. 2001;28(4):278-287. doi:10.1016/s1054-139x(00)00184-1.

15. Bamidele AR, Hoque ME, Van Der Heever $H$. Patient satisfaction with the quality of care in a primary health care setting in Botswana. S Afr Fam Pract. 2011;53(2):170-175. doi: 10.1080/20786204.2011.10874080.

16. Quintana JM, González N, Bilbao A, et al. Predictors of patient satisfaction with hospital health care. BMC Health Serv Res. 2006;6:102. doi:10.1186/1472-6963-6-102.

17. Ghana Statistical Service. 2010 Population \& Housing Census Report: District Analytical Report, Tema Metropolitan Assembly. Ghana: Ghana Statistical Service; 2014.

18. Dickson KE, Ashton J, Smith JM. Does setting adolescent-friendly standards improve the quality of care in clinics? evidence from South Africa. Int J Qual Health Care. 2007;19(2):80-89. doi:10.1093/intqhe/mzl070.

19. Pallant J. SPSS Survival manual. London, UK: McGraw-Hill Education; 2013.

20. Dagnew T, Tessema F, Hiko D. Health service utilization and reported satisfaction among adolescents in Dejen district, Ethiopia: a cross-sectional study. Ethiop J Health Sci. 2015;25(1):17-28. doi:10.4314/ejhs.v25i1.4.

21. Chisolm DJ, Gardner W, Julian T, Kelleher KJ. Adolescent satisfaction with computer-assisted behavioural risk screening in primary care. Child Adolesc Ment Health. 2008;13(4):163168. doi:10.1111/j.1475-3588.2007.00474.x.
22. Turchik JA, Karpenko V, Ogles BM, Demireva P, Probst DR. Parent and adolescent satisfaction with mental health services: does it relate to youth diagnosis, age, gender, or treatment outcome? Community Ment Health J. 2010;46(3):282-288. doi:10.1007/s10597-010-9293-5.

23. Awang H, Ab Rahman A, Sukeri S, Hashim N, Nik Abdul Rashid NR. Adolescent-friendly health services in primary healthcare facilities in Malaysia and its correlation with adolescent satisfaction level. Int J Adolesc Youth. 2020;25(1):551-561. doi :10.1080/02673843.2019.1685556.

24. Hoopes AJ, Agarwal P, Bull S, Chandra-Mouli V. Measuring adolescent friendly health services in India: a scoping review of evaluations. Reprod Health. 2016;13(1):137. doi:10.1186/ s12978-016-0251-8.

25. Geary RS, Gómez-Olivé FX, Kahn K, Tollman S, Norris SA. Barriers to and facilitators of the provision of a youth-friendly health services programme in rural South Africa. BMC Health Serv Res. 2014;14:259. doi:10.1186/1472-6963-14-259.

26. Kennedy EC, Bulu S, Harris J, Humphreys D, Malverus J, Gray NJ. "Be kind to young people so they feel at home": a qualitative study of adolescents' and service providers' perceptions of youth-friendly sexual and reproductive health services in Vanuatu. BMC Health Serv Res. 2013;13:455. doi:10.1186/1472-6963-13-455.

27. Biering P. Child and adolescent experience of and satisfaction with psychiatric care: a critical review of the research literature. J Psychiatr Ment Health Nurs. 2010;17(1):65-72. doi:10.1111/ j.1365-2850.2009.01505.x.

28. Chandra-Mouli V, Chatterjee S, Bose K. Do efforts to standardize, assess and improve the quality of health service provision to adolescents by government-run health services in low and middle income countries, lead to improvements in service-quality and service-utilization by adolescents? Reprod Health. 2016;13:10. doi:10.1186/s12978-015-0111-y.

29. Kaplan S, Busner J, Chibnall J, Kang G. Consumer satisfaction at a child and adolescent state psychiatric hospital. Psychiatr Serv. 2001;52(2):202-206. doi:10.1176/appi.ps.52.2.202.

30. Garland AF, Haine RA, Boxmeyer CL. Determinates of youth and parent satisfaction in usual care psychotherapy. Eval Program Plann. 2007;30(1):45-54. doi:10.1016/j. evalprogplan.2006.10.003.

31. Schriver B, Meagley K, Norris S, Geary R, Stein AD. Young people's perceptions of youth-oriented health services in urban Soweto, South Africa: a qualitative investigation. BMC Health Serv Res. 2014;14:625. doi:10.1186/s12913-014-0625-y.

32. Lim SW, Chhabra R, Rosen A, Racine AD, Alderman EM. Adolescents' views on barriers to health care: a pilot study. J Prim Care Community Health. 2012;3(2):99-103. doi:10.1177/2150131911422533.

33. Bankole A, Malarcher S. Removing barriers to adolescents' access to contraceptive information and services. Stud Fam Plann. 2010;41(2):117-124. doi:10.1111/j.17284465.2010.00232.x.

34. Chilinda I, Hourahane G, Pindani M, Chitsulo C, Maluwa A. Attitude of health care providers towards adolescent sexual and reproductive health services in developing countries: a systematic review. Health. 2014;6(14):1706-1713. doi:10.4236/health.2014.614203. 